\title{
Photosynthetic parameters in the Beaufort Sea in relation to the phytoplankton community structure
}

\author{
Y. Huot ${ }^{1}$, M. Babin ${ }^{2}$, and F. Bruyant ${ }^{2}$ \\ ${ }^{1}$ Centre d'Applications et de Recherches en Télédétection, Département de géomatique appliquée, Université de Sherbrooke, \\ Sherbrooke, QC J1C 2R1, Canada \\ ${ }^{2}$ UMI3376 “Takuvik” Université Laval - CNRS, Pavillon Alexandre Vachon, 1045, Avenue de la Médecine, Université Laval, \\ Québec City, QC G1V 0A6, Canada
}

Correspondence to: Y. Huot (yannick.huot@usherbrooke.ca)

Received: 28 December 2012 - Published in Biogeosciences Discuss.: 30 January 2013

Revised: 23 April 2013 - Accepted: 25 April 2013 - Published: 29 May 2013

\begin{abstract}
To model phytoplankton primary production from remotely sensed data, a method to estimate photosynthetic parameters describing the photosynthetic rates per unit biomass is required. Variability in these parameters must be related to environmental variables that are measurable remotely. In the Arctic, a limited number of measurements of photosynthetic parameters have been carried out with the concurrent environmental variables needed. Such measurements and their relationship to environmental variables will be required to improve the accuracy of remotely sensed estimates of phytoplankton primary production and our ability to predict future changes. During the MALINA cruise, a large dataset of these parameters was obtained. Together with previously published datasets, we use environmental and trophic variables to provide functional relationships for these parameters. In particular, we describe several specific aspects: the maximum rate of photosynthesis $\left(P_{\max }^{\text {chl }}\right)$ normalized to chlorophyll decreases with depth and is higher for communities composed of large cells; the saturation parameter $\left(E_{\mathrm{k}}\right)$ decreases with depth but is independent of the community structure; and the initial slope of the photosynthesis versus irradiance curve $\left(\alpha^{\mathrm{chl}}\right)$ normalized to chlorophyll is independent of depth but is higher for communities composed of larger cells. The photosynthetic parameters were not influenced by temperature over the range encountered during the cruise $\left(-2\right.$ to $\left.8^{\circ} \mathrm{C}\right)$.
\end{abstract}

\section{Introduction}

The impact of climate change in the Arctic is more immediate and stark than what models were predicting even a few years ago. As models are improved to match current observations, the first ice-free summer in the Arctic Ocean is not expected in the 22nd century (Walsh et al., 2005) anymore but instead in a matter of decades (Stroeve et al., 2012; Wang and Overland, 2012). Furthermore, it is increasingly obvious that the response of the ecosystem will be dramatic. From chemical changes in the water (e.g., Yamamoto et al., 2012) to community shifts in primary producers (e.g., Li et al., 2009) to declines in populations of large mammals (Maccracken, 2012; Stirling and Derocher, 2012), many changes are rapid, and populations that cannot adapt will face sharp declines. A major uncertainty in the ecosystem response to these changes is the impact on primary producers, the basic source of energy to the food web. Therefore, an understanding of the consequences of climate change requires estimates of present and future changes in primary production.

A few researchers have already undertaken such efforts using remote sensing data (e.g., Brown and Arrigo, 2012; Pabi et al., 2008) or modeling approaches (e.g., Lavoie et al., 2010). Generally, these studies find that the increased light due to decreasing sea ice cover leads to higher primary production though these increases may be dampened by nutrient limitation (Hill et al., 2013; Codispoti et al., 2013). Obtaining these results requires an estimate of the available light, the biomass present, and the efficiency of photosynthesis per unit biomass (i.e., the biomass-specific photosynthetic rates) 
at different depths. While estimates of light and biomass are obtained either through remote sensing or modeling, the biomass-specific photosynthetic rates require field measurements. These observations are very limited in the Arctic, thus making the model parameterizations difficult. Furthermore, since considerable variability is observed in the biomassspecific photosynthetic rates, a significant amount of work is still needed to find appropriate relationships between these measurements and independent variables that can be estimated remotely or in situ. To this end, the most common independent variables are temperature, nutrient concentrations, growth irradiance, community structure, or some combination of these variables (e.g., Behrenfeld and Falkowski, 1997; Huot et al., 2007; Platt et al., 2008; Uitz et al., 2008; Behrenfeld et al., 2002).

A common approach to estimate the biomass-specific photosynthetic rates is to incubate several water samples in laboratory incubators for tens of minutes to a few hours under the range of irradiance encountered in situ at the depth of sampling. This results in a curve that represents the rate of photosynthesis $\left(P, \mathrm{mg} \mathrm{Cm}^{-3} \mathrm{~h}^{-1}\right)$ as a function of irradiance (PvsE curve). The PvsE curve can be described using a functional form and a few parameters, usually two to four, depending on the shape of the curve and the model used (c.f. Jassby and Platt, 1976; Platt et al., 1980). These parameters are the so-called "photosynthetic parameters" and three are most often described: the maximum rate of photosynthesis $\left(P_{\max }, \mathrm{mg} \mathrm{C} \mathrm{m}^{-3} \mathrm{~h}^{-1}\right)$, the initial slope of the PvsE curve $\left(\alpha, \mathrm{mg} \mathrm{C} \mathrm{m}^{-3} \mathrm{~h}^{-1}\left[\mu \mathrm{mol} \text { photon } \mathrm{m}^{-2} \mathrm{~s}^{-1}\right]^{-1}\right)$, and the saturation irradiance $\left(E_{\mathrm{k}}=P_{\max } / \alpha, \mu\right.$ mol photon $\left.\mathrm{m}^{-2} \mathrm{~s}^{-1}\right)$. The photosynthetic curves computed using the retrieved parameters can be normalized to a proxy of biomass (or photosynthetic absorption), generally the chlorophyll $a$ concentration ([chl], $\mathrm{mg} \mathrm{m}^{-3}$ ), to obtain a biomass-specific rate of photosynthesis $\left(P^{\mathrm{chl}}, \mathrm{mgC} \mathrm{mg} \mathrm{chl}{ }^{-1} \mathrm{~h}^{-1}\right)$. These biomassnormalized PvsE curves can be applied to remote sensing or in situ measurements of biomass, and the primary productivity can be computed using modeled or measured light profiles (e.g., Morel, 1991; Longhurst et al., 1995; Antoine et al., 1996).

Photosynthetic parameters have been documented in the Arctic Ocean, but only to a limited extent because of its remoteness. A dataset of PvsE collected over several years by the Marine Ecology Laboratory (MEL) at the Bedford Institute of Oceanography is presently the largest available. This dataset allowed the first estimates of primary production in Arctic waters (Subba Rao and Platt, 1984). However, the variability in the MEL dataset could only be partly explained based on relationships with depth (light) and temperature. While the dataset contains information about nutrients, it does not contain information about species composition to assess the potential link between community structure and photosynthetic parameters. A study by Rey (1991), conducted over several years and seasons in the Barents Sea, arrived at similar conclusions: the PvsE parameters appear to be controlled by light and temperature. They furthermore observed important seasonal differences. No information was available about the community structure. Reviewing the literature regarding polar waters, Sakshaug and Slagstad (1991) highlighted the lower chlorophyll-normalized rates of photosynthesis in the Arctic compared to more temperate regions. More recently, a study comprising 15 PvsE curves from the Beaufort Sea, the same region as in our study, was published (Palmer et al., 2011); however, the small size of the dataset limits the significance of the relationships with in situ parameters.

In this study, we examine data from the Beaufort Sea during the period of the MALINA cruise (30 July to 27 August 2009). We describe the photosynthetic parameters and provide functions of environmental variables that can be used to estimate them. These functions could, in turn, be used to estimate primary production in the Beaufort Sea during oligotrophic periods similar to those encountered during the MALINA cruise. By comparing our dataset with the MEL dataset, we extend our functional relationships to more eutrophic conditions.

\section{Methods}

Data were collected as part of the MALINA cruise that was conducted in the southern Beaufort Sea (approximately 69$72^{\circ} \mathrm{N}$ and $125-145^{\circ} \mathrm{W}$ ) from 30 July to 27 August 2009 aboard the icebreaker CCGS Amundsen. Generally, two to three stations per day were visited and sampled for the variables below between about 08:00 and 19:00 local time.

PvsE curves: the PvsE curves as well as the estimates for the photophysiological parameters were carried out according to Babin et al. (1994) using a radial photosynthetron and a metal halide lamp with the slightly modified methods, including fitting an exponential model with an intercept and quality controls, described in Huot et al. (2007). This protocol allows the determination of multiple simultaneous PvsE curves from the surface to depth. In most cases, six curves were obtained for each station distributed from the surface to just below the subsurface chlorophyll maximum (generally near 60 to $70 \mathrm{~m}$ during the cruise), which was a persistent feature in the area at the time of the cruise. To obtain sufficient signal, incubation time was between 2 and $4 \mathrm{~h}$ depending on the chlorophyll concentration. All data were normalized to the chlorophyll $a$ concentration determined by HPLC, which was collected following the method described in Ras et al. (2008). This normalization is denoted with the superscript "chl" for the parameters. This provided a total of 231 curves. After our quality controls measures, which consisted of keeping parameters for which the $95 \%$ confidence interval on the parameter was less than $60 \%$ of the value of the fit, this led to 179 values of $P_{\max }^{\mathrm{chl}}, 137$ values of $\alpha^{\mathrm{chl}}$, and 130 values of $E_{\mathrm{k}}$. Unless otherwise noted, the light data used in this study are expressed in terms of photosynthetically available 
radiation (PAR, $\mu$ mol photon $\mathrm{m}^{-2} \mathrm{~s}^{-1}$ ) and were measured in the photosynthetron using a scalar sensor (Biospherical Instruments Inc., USA). For future comparisons with data from other sources and for models using photosynthetically usable radiation (PUR, $\mu$ mol photon $\mathrm{m}^{-2} \mathrm{~s}^{-1}$; Morel, 1978), we note that, by using the phytoplankton absorption spectra computed using the parameterization of Ciotti et al. (2002) with an $S_{\langle f\rangle}$ of 0.5 , the results for $E_{\mathrm{k}}$ and $\alpha^{\text {chl }}$ can be transformed to PUR by respectively multiplying $E_{\mathrm{k}}$ by 0.35 and dividing $\alpha^{\text {chl }}$ by 0.35 (the ratio of PUR to PAR irradiance during the incubation) using the following equation to compute PUR,

$\mathrm{PUR}=\int_{400}^{700} \frac{a_{\varphi}(\lambda)}{a_{\varphi \max }} \cdot \stackrel{\mathrm{o}}{E}(\lambda) \cdot d \lambda$,

where $a_{\varphi}(\lambda)$ is the phytoplankton absorption coefficient, $a_{\varphi \max }$ is the maximum value of $a_{\varphi}(\lambda)$ and $\stackrel{\mathrm{o}}{E}(\lambda)$ is the spectral scalar irradiance. When the absorption spectrum measured for each sample is used instead of the absorption from Ciotti et al. (2002), we find that the multiplication factor is on average 0.35 with a standard deviation of $0.04(N=231)$. However, using the extreme phytoplankton absorption spectrum $\left(S_{\langle f\rangle}=1\right.$ or 0$)$ proposed by Ciotti et al. (2002) with our lamp would change the multiplication factor from 0.26 to 0.89 for the picoplankton $\left(S_{\langle f\rangle}=1\right)$ and the macroplankton $\left(S_{\langle f\rangle}=0\right)$ spectra, respectively. Using absorption spectra that have shapes that are similar to those measured in situ is thus important in these computations; in our case this was possible using an $S_{\langle f\rangle}$ of 0.5 .

For comparison with our own dataset, data from a series of reports from the Marine Ecology Laboratory at the Bedford Institute of Oceanography (Irwin et al., 1978a, b, 1980, 1982, 1983a, b, 1984a, b, 1985) were retrieved for all stations north of $60^{\circ} \mathrm{N}$. This provided a total of $350 \mathrm{PvsE}$ curves. Most of this dataset has been analyzed thoroughly by Harrison and Platt (1986). This dataset mostly covers regions of the eastern Canadian Arctic including the Labrador Sea and Shelf, Hudson Bay and Strait, Lancaster Sound, Foxe Basin, Davis Strait, Baffin Bay, and Jones Sound.

Community size and taxonomy: to describe the fraction of the chlorophyll- $a$ corresponding to different size fractions we use the method developed by Uitz et al. (2006) based on marker pigments from the HPLC dataset. As noted by Uitz et al. (2006), the size classes are in reality taxonomic classes. For example, some diatoms species whose physical size would place them as nanoplankton would be classified by the method as microplankton since fucoxanthin is used as a marker pigment for microplankton.

\section{Results and discussion}

The $P_{\max }^{\mathrm{chl}}$ values measured during the MALINA cruise were generally lower than those reported in the MEL reports
(Fig. 1a). Indeed, the region we studied is different from those in the MEL reports, which mostly include data from the eastern Canadian Arctic. We also note that the trophic state of the waters encountered during the MALINA cruise and during the MEL cruises were quite different. The Beaufort Sea had very low [chl] during the MALINA cruise. The cruise median for the samples from the top $10 \mathrm{~m}$ was $0.09 \mathrm{mg} \mathrm{m}^{-3}$ with a 25 th and 75 th percentile of 0.06 and $0.11 \mathrm{mg} \mathrm{m}^{-3}$. On the other hand, in the MEL dataset only 5 out of 187 samples had a surface chlorophyll concentration below $0.13 \mathrm{mg} \mathrm{m}^{-3}$ for the top $10 \mathrm{~m}$. The median of the MEL dataset for the top $10 \mathrm{~m}$ is $0.7 \mathrm{mg} \mathrm{m}^{-3}$ with the 25th and 75th percentiles at 0.36 and $1.68 \mathrm{mg} \mathrm{m}^{-3}$, respectively. The oligotrophic state may have led to the lower $P_{\max }^{\mathrm{chl}}$ values for the MALINA dataset. The frequency distributions of $\alpha^{\mathrm{chl}}$ and $E_{\mathrm{k}}$ for the PvsE curves are presented in Fig. $1 \mathrm{~b}$ and c, respectively. A comparison with the MEL data is more difficult for these parameters as no spectra for the incubator irradiance sources used in the MEL data are available, the type of lamps were changed between years, and the absorption spectra are not available. To avoid misrepresenting the MEL data, we did not compare these data. For similar reasons, a comparison with any other dataset is difficult. This is the reason why we provide (see Methods) the relationship with PUR using a standard phytoplankton absorption spectrum, which should allow comparisons with other PUR-based measurements.

The phytoplankton community composition as described using the percent of chlorophyll $a$ attributed to different phytoplankton groups derived from pigment composition varied during the cruise depending on the station and depth (Fig. 2). Waters in the upper $50 \mathrm{~m}$ were typically dominated by picoplankton (similar to what was found by Lovejoy et al., 2007), or occasionally by microplankton, while deeper waters were typically dominated by nanoplankton. For all depths and samples, the microplankton fraction amounted to less than $40 \%$ of the phytoplankton community biomass for $82 \%$ of the 231 PvsE samples.

As previously observed in many datasets of PvsE curves (e.g., Harrison and Platt, 1986; see Discussion Sakshaug and Slagstad, 1991, and a review in Behrenfeld et al., 2004), we observed a correlation between $P_{\max }^{\mathrm{chl}}$ and $\alpha^{\mathrm{chl}}$ (Fig. 3). The depth dependence of this linear relationship is quite strong; the slope of a hypothetical regression between $P_{\max }^{\text {chl }}$ and $\alpha^{\text {chl }}$ decreases with depth (also observed by Behrenfeld et al., 2004), which in fact reflects a decrease in $E_{\mathrm{k}}$ with increasing depth (see below) and is consistent with photoadaptation (changes linked to different genes) and photoacclimation (changes linked to different quota of cellular constituents without genetic changes) processes. The last variable, illustrated by the size of the symbols in Fig. 3, is the fraction of microplankton in the sample. We can see qualitatively that samples with a higher fraction of microplankton in the sample tend to have higher values of $P_{\max }^{\mathrm{chl}}$ and $\alpha^{\mathrm{chl}}$.

The $P_{\max }^{\mathrm{chl}}$ decreased continuously with depth, which is consistent with the photoacclimation and photoadaptation 

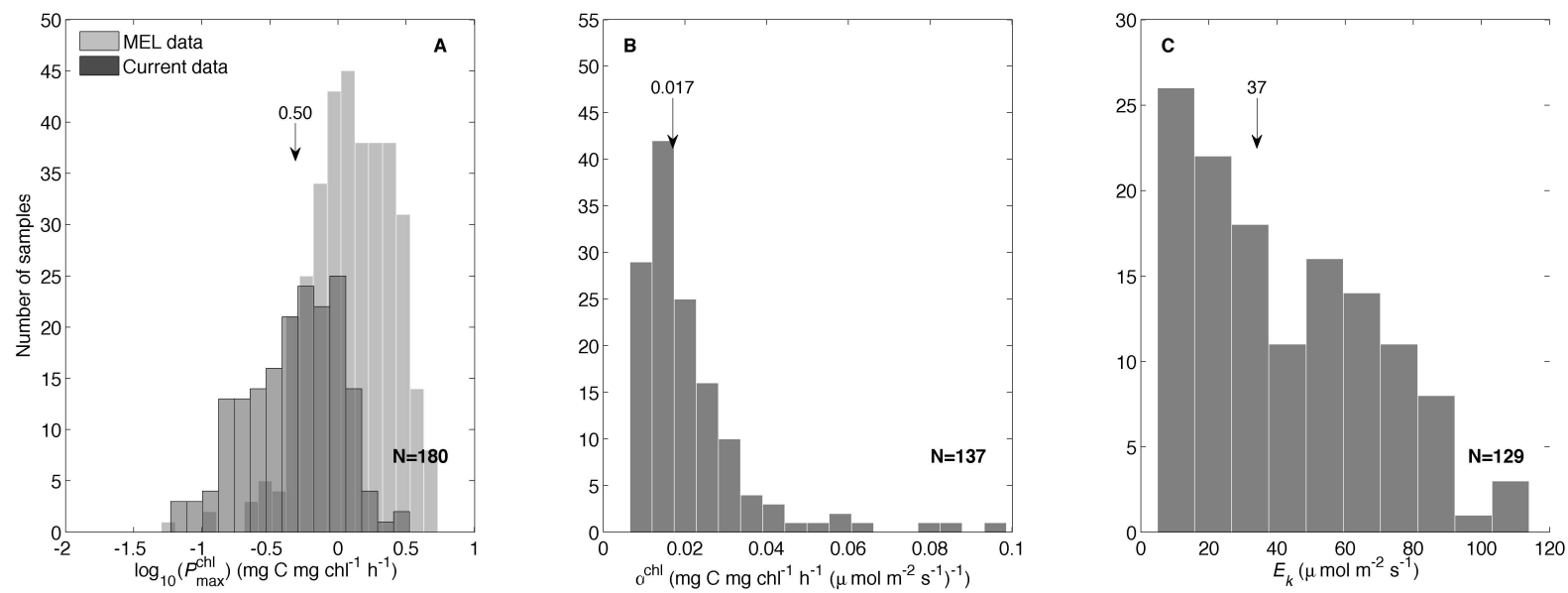

Fig. 1. Distribution of photosynthetic parameters measured during the MALINA cruise. (A) $P_{\max }^{\text {chl }}$, (B) $\alpha^{\text {chl }}$, and (C) $E_{\mathrm{k}}$. Numbers with arrows represent the average value of the dataset.

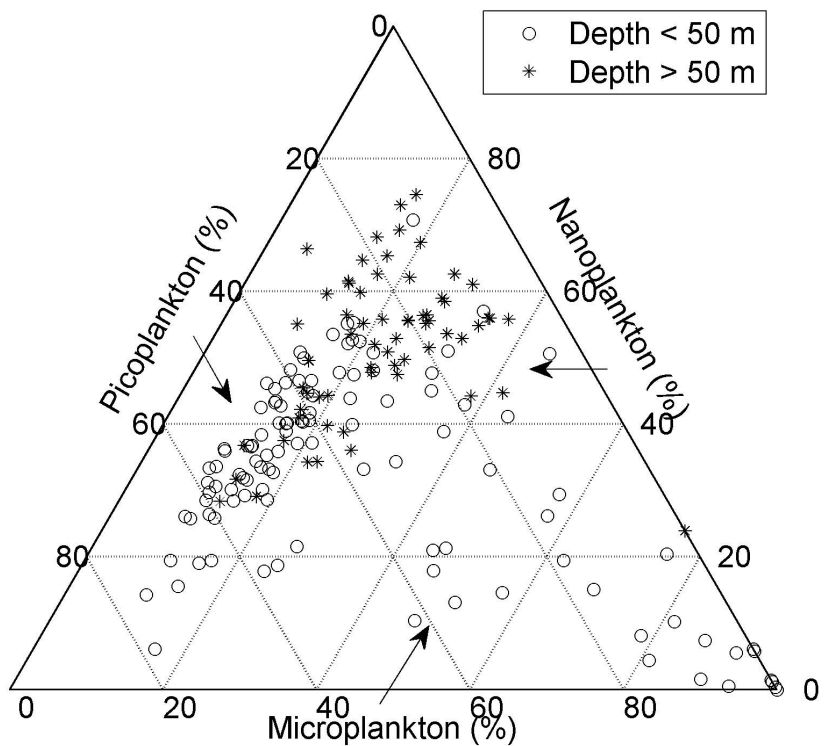

Fig. 2. Description of the phytoplankton communities using the percent contribution to the total chlorophyll $a$ concentration and separated into two depth intervals. The size classes were obtained using HPLC pigments following Uitz et al. (2006). Arrows represent the direction of the grid line associated with each variable.

(c.f. Falkowski and LaRoche, 1991) of cells (Fig. 4a). Given the changes in phytoplankton groups with depth, photoadaptation is clearly responsible for at least part of this decrease. It is important to note, however, that relationships with the optical depth provided less predictive power than relationships with depth. We believe that this results from the lack of accurate measurements of in situ irradiance coinciding with the PvsE samples, and thus does not reflect a real feature of these systems; while precise irradiance measurements were made during the cruise, these were not collocated and simul-

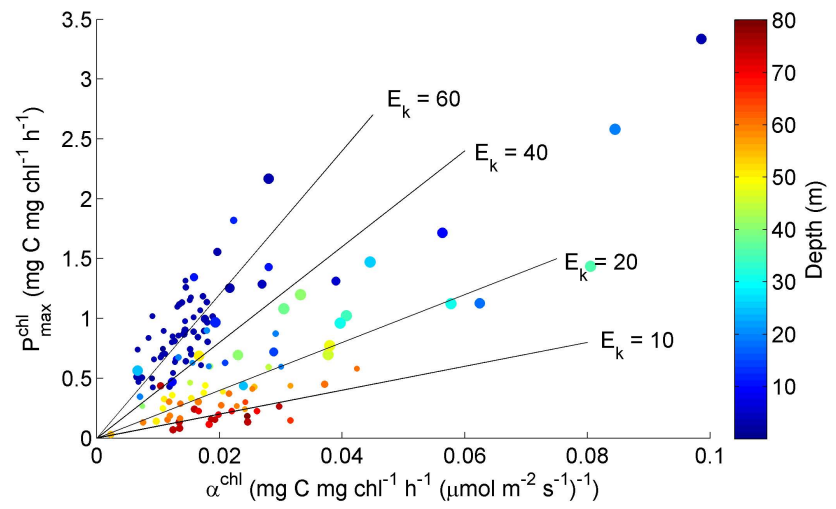

Fig. 3. Relationship between $P_{\max }^{\mathrm{chl}}$ and $\alpha^{\mathrm{chl}}$. Points are colored according to depth (see colorscale), while the increasing size of the points represents an increasing fraction of microplankton in the phytoplankton community.

taneous with the PvsE sampling. That being said, a similar observation was made by Huot et al. (2007) for the Southern Pacific Ocean, where excellent measurements of irradiance were available. In any case, below we parameterize these changes as a function of depth rather than the optical depth. Besides depth, very little of the remaining variability could be explained by the variables tested: nutrient concentrations, temperature (see Fig. 5, described later), previous day photon dose, etc. However, the dataset could be well separated using the microplankton fraction (color scale in Fig. 4a), which was derived using the pigment composition by the method described in Uitz et al. (2006). Samples that had a microplankton fraction greater than 0.65 had significantly higher $P_{\max }^{\mathrm{chl}}$. This is highlighted in Fig. $4 \mathrm{~b}$ for depths shallower than $50 \mathrm{~m}$, where all samples with a high microplankton fraction were located. This observation is consistent with the parameterization in Uitz et al. (2008) where microplankton (HPLC-based 
size classes) shows a higher $P_{\max }^{\mathrm{chl}}$ than other phytoplankton size classes. Palmer et al. (2011) also made a similar observation for the Beaufort Sea based on five samples from the subsurface chlorophyll maximum: the size fraction greater than $5 \mu \mathrm{m}$ had a higher $P_{\max }^{\mathrm{chl}}$ than that for the whole water sample.

For our dataset, three parameterizations with depth were derived. The first,

$P_{\max }^{\mathrm{chl}}=0.85 \cdot 10^{-7.2 \times 10^{-5} z^{2}-4.5 \times 10^{-3} z}$,

is for samples where the fraction of microplankton was lower than 0.65 , where $z(\mathrm{~m})$ is the depth. The second,

$P_{\max }^{\mathrm{chl}}=2.0 \cdot 10^{-8.7 \times 10^{-3} z}$,

is for samples where the fraction of microplankton was greater than 0.65 . While the last,

$P_{\max }^{\mathrm{chl}}=0.88 \cdot 10^{-1.2 \times 10^{-4} z^{2}-1.1 \times 10^{-3} z}$,

is for all of the MALINA data pooled.

The fit for the samples with a fraction of microplankton greater than 0.65 is very close to the fit for the whole MEL dataset (Fig. 4a). While this suggests that the differences between the MEL dataset and the present dataset can be attributed to different community structures linked to the different trophic states of the waters sampled, it is impossible to verify this interpretation. A closer look at the two datasets (Fig. 5a), however, provide some support to this hypothesis. Consistent with the results shown in Fig. 4a, points with a higher fraction of microplankton and higher chlorophyll concentration fit well within the cloud of points for the MEL dataset. However, without more overlap between the datasets and more information on the communities encountered during the MEL cruises, it is not clear whether the difference can be attributed to the ecology or to the methods used. The effect of temperature on $P_{\max }^{\text {chl }}$ over the range observed during the MALINA cruise is not significant; a temperature effect is not seen in the MEL dataset either (Fig. 5b). Notably, there is no relationship (not shown) between temperature and the microplankton fraction for the whole dataset.

Nevertheless, with the limited information available to date, and assuming that the differences between the datasets are not methodological, it appears reasonable to propose the high macroplankton relationship (Eq. 2) for [chl] above $\sim 0.1 \mathrm{mg} \mathrm{m}^{-3}$. This provides results that are in line with those of Harrison and Platt (1986). For lower [chl] concentrations, for which there does not appear to be other Arctic data available in the literature besides our study, Eq. (1) should be used. Using this parameterization with two size classes, the mean absolute percent error for the estimate of $P_{\max }^{\mathrm{chl}}$ is $31.6 \%$ (Fig. 4c). If these observations are confirmed by more Arctic measurements in the future, it will demonstrate an interesting difference with temperate and subtropical waters where $P_{\max }^{\text {chl }}$ is not strongly dependent on the trophic state
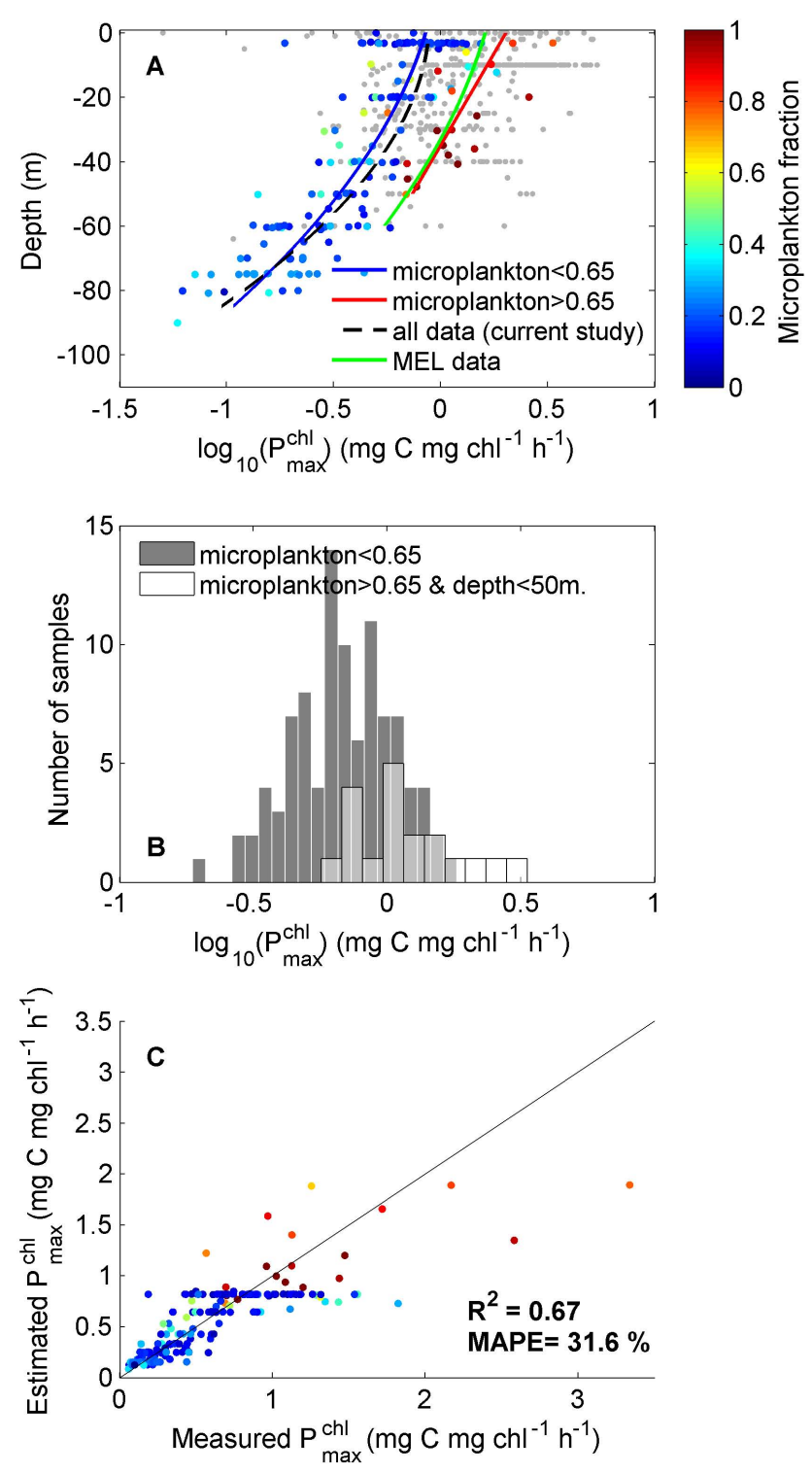

Fig. 4. Relationships for the photosynthetic parameter $P_{\max }^{\mathrm{chl}}$ during the MALINA cruise. (A) $P_{\max }^{\mathrm{chl}}$ as a function of depth and microplankton fraction (colorscale). Gray points represent the whole MEL dataset for which the fit (green line) is given by $P_{\max }^{\mathrm{chl}}=$ $1.611 \cdot 10^{-5.707 \times 10^{-5} z^{2}-4.427 \times 10^{-3} z}$. (B) Histogram of the $P_{\max }^{\mathrm{chl}}$ values for the two microplankton fraction intervals used in (A). (C) Predicted vs. measured values using Eqs. (1) and (2) (same colors as for $\mathbf{A})$.

of the water (e.g., Huot et al., 2007; Platt et al., 2008). The parameterization using two classes might also be useful for biogeochemical models, which attempt to predict the presence of more than one class.

We attempted to find further evidence in the literature that biomass-normalized photosynthesis is higher in large cells than small cells in Arctic waters. We thus turned to studies that measured size-fractionated depth-integrated primary 

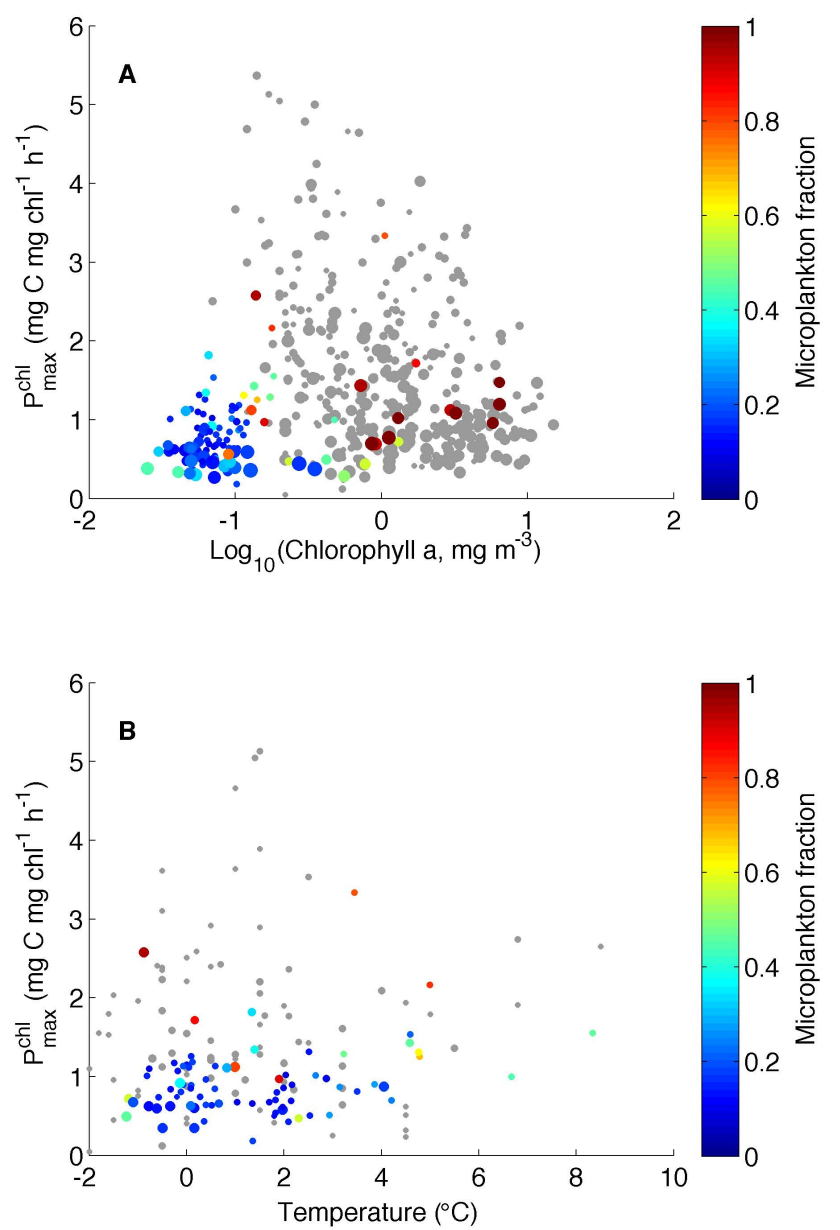

Fig. 5. Relationships between $P_{\max }^{\mathrm{chl}}$ and (A) chlorophyll concentration and (B) temperature. Colors represent the fraction of microplankton, while the size of the points represents depth. Gray points represent the MEL dataset. Only depths shallower than $50 \mathrm{~m}$ and $20 \mathrm{~m}$ are shown for $(\mathbf{A})$ and $(\mathbf{B})$, respectively.

production. There is, however, no clear trend observed and the results appear strongly dependent on the study site or the environment. Legendre et al. (1993, their Table 6) and Pesant et al. (1996, their Fig. 3) found that large cells are more efficient at photosynthesis per unit chlorophyll in Arctic waters. Sallon et al. (2011, their Table 5) and Brugel et al. (2009) found that primary production per unit biomass is equally efficient in small or large cells. Ardyna et al. (2011) had mixed results with some regions showing that small cells are more efficient, while, in other regions, large cells are more efficient per unit biomass. While the above studies used filtration for size fractionation, our size factor is based on marker pigments as the proxy for size. Thus it is possible that the differences in biomass-normalized photosynthetic rates are more linked to taxonomical changes (e.g., the presence of more diatoms) than to size classes resulting from size fractionation by filters with different mesh sizes.
Very clear evidence of photoacclimation and photoadaptation is seen with the depth dependence of the saturation irradiance $\left(E_{\mathrm{k}}\right.$, Fig. 6) for which the fit decreases from a value of about $69 \mu \mathrm{mol}$ photon $\mathrm{m}^{-2} \mathrm{~s}^{-1}$ at the surface to $8 \mu \mathrm{mol}$ photon $\mathrm{m}^{-2} \mathrm{~s}^{-1}$ at $85 \mathrm{~m}$. The best fit as a function of depth is given by the following relationship,

$E_{\mathrm{k}}=69 \cdot 10^{-0.011 z}$.

Multiplying by 0.35 provides the PUR equivalent: $E_{\mathrm{kPUR}}=$ $24 \cdot 10^{-0.011 z}$. Note that this decrease with depth is also clearly reflected in the relationship between $P_{\max }^{\text {chl }}$ and $\alpha^{c h l}$ (Fig. 3) as a decrease of the slope with depth for the samples.

It is noteworthy that these values are not affected by the fraction of microplankton in the water; all communities responded in the same way to changes in irradiance with depth. For comparison purposes (Fig. 7), we conducted the same analysis as Arrigo (1994, his Eqs. 10-13) to provide a fit to $E_{\mathrm{kPUR}}$, and we plotted the trends as a function of the mean in situ PUR for the last $24 \mathrm{~h}$ at the depth of sampling. We compare our results with the relationship provided by Arrigo (1994). Our dataset shows $E_{\mathrm{kPUR}}$ that are lower by a factor of about three. This is consistent with the lower $P_{\max }^{\text {chl }}$ observed (and a more-or-less-constant $\alpha^{\mathrm{chl}}$ ) leading to reduced values of the $E_{\mathrm{kPUR}}$ parameter. Although other explanations are possible, such as a different phytoplankton absorption spectrum, it is doubtful that such secondary effects could lead to the factor of three observed here. While both datasets are from polar waters, the dataset underlying Arrigo's relationship is mostly from Antarctic waters and certainly reflects different growth conditions, communities, and photophysiological states.

The parameter $\alpha^{\text {chl }}$ did not show significant trends with depth (Fig. 8a). Therefore, the average efficiency of light utilization at low irradiance was equal for all photoacclimation and photoadaptation levels. This is consistent with our current understanding of photoacclimation (MacIntyre et al., 2002). At each depth, however, there was nearly a factor-often 0variability in the measured values. As was the case for the $P_{\max }^{\mathrm{chl}}$ parameter, there was a clear difference in the samples with larger microplankton fractions, which explained a fraction of this variability (Fig. 8a and b). Using this observation, we derived three different values for $\alpha^{\text {chl }}$ (average \pm standard deviation): (1) for samples with a fraction of microplankton less than 0.65 , we used $\alpha^{\text {chl }}=0.017 \pm 0.007$; (2) for samples with a fraction of microplankton greater than 0.65 , we used $\alpha^{\text {chl }}=0.041 \pm 0.02$; and (3) for the whole dataset, we used $\alpha^{\mathrm{chl}}=0.021 \pm 0.01$. These relationships could be used in a similar fashion to that proposed for $P_{\max }^{\mathrm{chl}}$ (e.g., Fig. 8c). Dividing by 0.35 provides the PUR values.

Using the relationships described above for $P_{\max }^{\mathrm{chl}}$ and $E_{\mathrm{k}}$, Fig. 9 illustrates the main changes observed in the PvsE curves in these waters as a function of depth and trophic status. In particular, it highlights the important difference in $P_{\max }^{\mathrm{chl}}$ between the samples with a larger fraction of microplankton and those with a smaller fraction. It also 


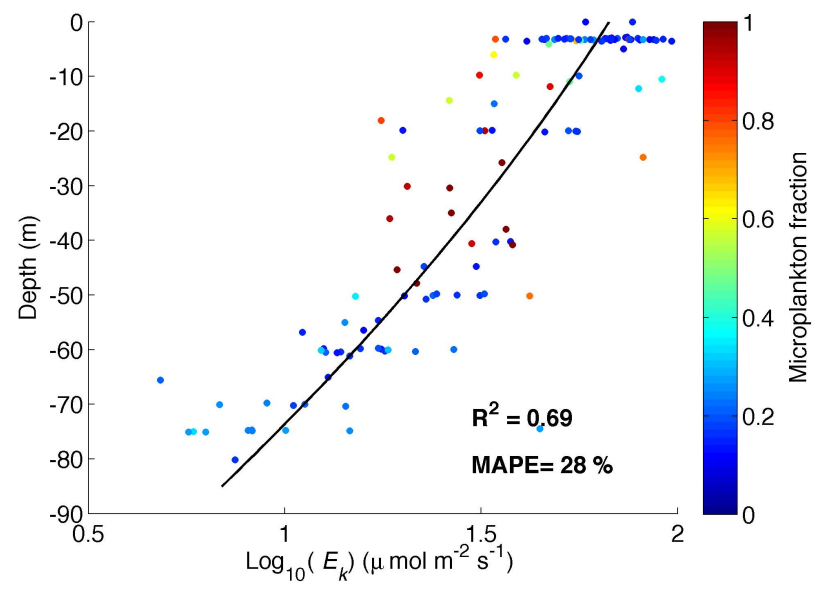

Fig. 6. Depth dependence of the photosynthetic parameter $E_{\mathrm{k}}$. Colors represent the fraction of microplankton (see colorbar and Fig. 2 for details).

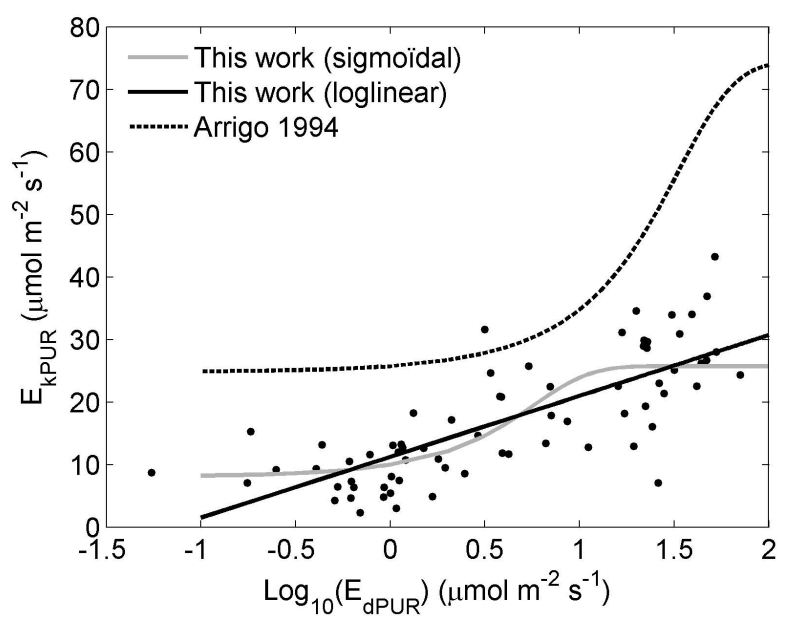

Fig. 7. Relationship between $E_{\mathrm{kPUR}}$ and the average daily PUR irradiance within the water column (see Arrigo, 1994, for details of the calculations). Of the two regressions $(N=70)$ for our dataset, one is consistent with the sigmoidal functional form of Arrigo (1994) and the other is a loglinear regression: $E_{\mathrm{kPUR}}=$ $11.2+9.73 \log _{10}\left(E_{\mathrm{dPUR}}\right)$.

highlights the constant $\alpha^{\text {chl }}$ observed with depth and the rapid decrease in $P_{\max }^{\mathrm{chl}}$ with depth accompanied by a decreasing $E_{\mathrm{k}}$.

Short-term incubations allowed us to obtain a large number of samples in a relatively short time. The construction of PvsE curves at many depths allows easy modeling of primary production for any irradiance at any depth. As with the longer-term incubations, short-term incubations, however, suffer from their limitations (Cullen, 2001; Marra, 2002). In the case of short-term incubations, the most limiting problem lies in the interpretation of the measurements, in particular whether the gross or net primary production was measured. To know where the measurement falls between these two
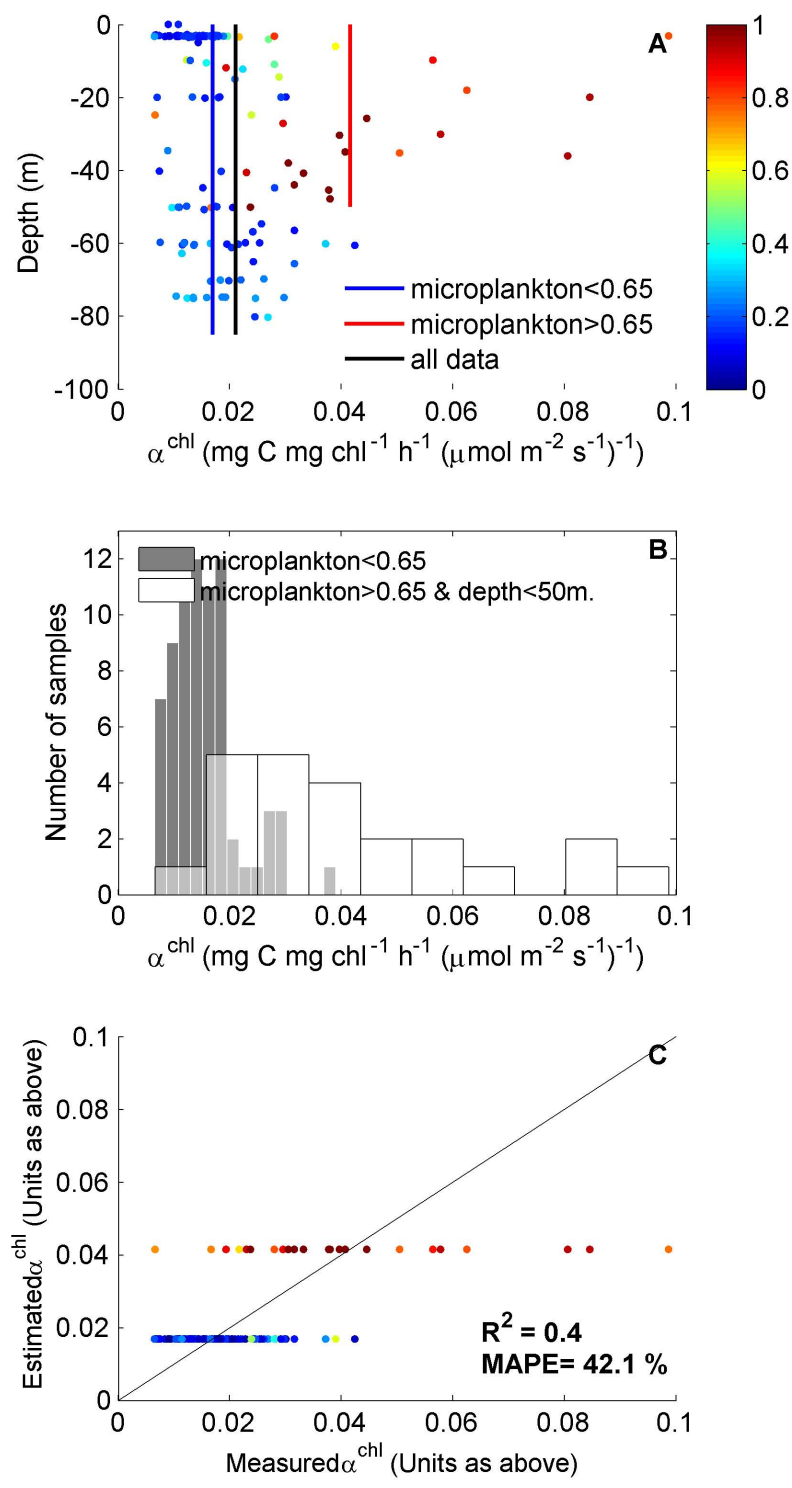

Fig. 8. Relationship of $\alpha^{\text {chl }}$ with depth and microplankton fraction. (A) Depth dependence of $\alpha^{\mathrm{chl}}$. Colors represent microplankton fractions. (B) Histogram of the $\alpha^{c h l}$ values for different intervals of the microplankton fraction. (C) Predicted vs. estimated values of $\alpha^{\text {chl }}$ using the two curves for microplankton less than 0.65 and microplankton greater than 0.65 (A).

extremes, the growth rates must be known (Dring and Jewson, 1982; Halsey et al., 2010, 2011); we did not have such measurements during the cruise. Previous measurements performed in the Arctic, however, suggest that with the right model, calculations made with PvsE curves of the dailyintegrated primary production obtained from 2 to $4 \mathrm{~h}$ incubation provide equivalent results to deck incubations for $24 \mathrm{~h}$ (Harrison et al., 1985). 


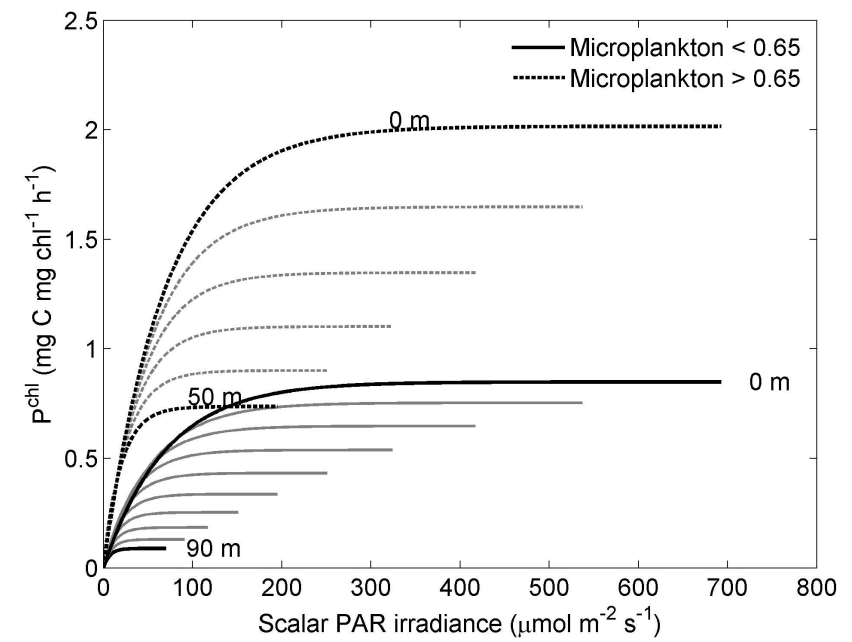

Fig. 9. Modeled PvsE curves using the parameterization derived in this study for $P_{\max }^{\text {chl }}\left(\right.$ Eqs. 1 and 2) and $E_{\mathrm{k}}$ (Eq. 4). Gray curves represent depth increments of $10 \mathrm{~m}$ between the surface $(0 \mathrm{~m})$ and the deepest curve $(50 \mathrm{~m}$ for a microplankton fraction greater than 0.65 and $90 \mathrm{~m}$ for a microplankton fraction less than 0.65). Curves were plotted up to 10 times the irradiance of their respective $E_{\mathrm{k}}$ values.

\section{Conclusions}

The large number of PvsE curves collected in the Beaufort Sea as part of the MALINA cruise provided a dataset to characterize the photosynthetic parameters of the phytoplanktonic community. It highlighted three key aspects: (1) the maximum photosynthetic rates and saturation irradiance for the phytoplankton were lower than in other regions in polar waters; (2) strong gradients with depth were observed for $P_{\max }^{\mathrm{chl}}$ and $E_{\mathrm{k}}$, while $\alpha^{\text {chl }}$ remained constant; and (3) the community structure was the most important parameter influencing the remaining variability in this dataset.

The very oligotrophic conditions encountered during the sampling conditions make this dataset unique in Arctic research; however, they also limit the applicability of the relationships to conditions similar to those encountered during the cruise. Indeed, for most of the Canadian Arctic, as seen in our comparison with the MEL dataset, it appears that the relationships obtained for the samples with a larger microplankton fraction are more appropriate.

Acknowledgements. This work was supported by the Canada Research Chairs program and a grant from the NSERC Discovery Program to Y. H. We thank the captain and crew of the CCGS Amundsen. We are also thankful to $\mathrm{M}$. Gosselin for sharing facilities and advices and to Joannie Ferland for compiling a large dataset of cruise data.

Edited by: E. Boss

\section{References}

Antoine, D., André, J. M., and Morel, A.: Oceanic primary production 2. Estimation at global scale from satellite (coastal zone color scanner) chlorophyll, Global. Biogeochem. Cy., 10, 57-69, 1996.

Ardyna, M., Gosselin, M., Michel, C., Poulin, M., and Tremblay, É.: Environmental forcing of phytoplankton community structure and function in the Canadian High Arctic: contrasting oligotrophic and eutrophic regions, Mar. Ecol.-Prog. Ser., 442, 3757, doi:10.3354/meps09378, 2011.

Arrigo, K. R.: Impact of ozone depletion on phytoplankton growth in the Southern Ocean: large-scale spatial and temporal variability, Mar. Ecol.-Prog. Ser., 114, 1-12, 1994.

Babin, M., Morel, A., and Gagnon, R.: An incubator designed for extensive and sensitive measurements of phytoplankton photosynthetic parameters, Limnol. Oceanogr., 39, 694-702, 1994.

Behrenfeld, M. J. and Falkowski, P. G.: Photosynthetic rates derived from satellite-based chlorophyll concentration, Limnol. Oceanogr., 42, 1-20, 1997.

Behrenfeld, M. J., Maranon, E., Siegel, D. A., and Hooker, S. B.: Photoacclimation and nutrient-based model of light-saturated photosynthesis for quantifying oceanic primary production, Mar. Ecol.-Prog. Ser., 228, 103-117, 2002.

Behrenfeld, M. J., Prasil, O., Babin, M., and Bruyant, F.: In search of a physiological basis for covariations in light-limited and light-saturated photosynthesis, J. Phycol., 40, 4-25, 2004.

Brown, W. and Arrigo, . R.: Contrasting trends in sea ice and primary production in the Bering Sea and Arctic Ocean, ICES. J. Mar. Sci., 69, 1180-1193, doi:10.1093/icesjms/fss113, 2012.

Brugel, S., Nozais, C., Poulin, M., Tremblay, E., Miller, A., Simpson, G., Gratton, Y., and Demers, S.: Phytoplankton biomass and production in the southeastern Beaufort Sea in autumn 2002 and 2003, Mar. Ecol.-Prog. Ser., 377, 63-77, doi:10.3354/meps07808, 2009.

Ciotti, M., Lewis, M. R., and Cullen, J. J.: Assessment of the relationship between dominant cell size in natural phytoplankton communities and the spectral shape of the absorption coefficient, Limnol. Oceanogr., 47, 404-417, 2002.

Codispoti, A., Kelly, V., Thessen, A., Matrai, P., Suttles, S., Hill, V., and Light, B.: Synthesis of primary production in the arctic ocean: III. Nitrate and phosphate based estimates of net community production, Progr. Oceanogr., 110, 126-150, doi:10.1016/j.pocean.2012.11.006, 2013.

Cullen, J. J.: Primary production methods, in: Encyclopedia of ocean sciences, edited by: Steele, J. H., 2277-2284, Academic, 2001.

Dring, M. J. and Jewson, D. H.: What does ${ }^{14} \mathrm{C}$ uptake by phytoplankton really measure? A theoretical modelling approach, $\mathrm{P}$. Roy. Soc. Lond. B, 214, 351-368, 1982.

Falkowski, P. G. and LaRoche, J.: Acclimation to spectral irradiance in algae, J. Phycol., 27, 8-14, 1991.

Halsey, K. H., Milligan, A. J., and Behrenfeld, M. J.: Physiological optimization underlies growth rate-independent chlorophyllspecific gross and net primary production, Photosynthesis Res., 103, 125-137, doi:10.1007/s11120-009-9526-z, 2010.

Halsey, K. H., Milligan, A. J., and Behrenfeld, M. J.: Linking timedependent carbon-fixation efficiencies in dunaliella tertiolecta (chlorophyceae) to underlying metabolic pathways, J. Phycol., 47, 66-76, doi:10.1111/j.1529-8817.2010.00945.x, 2011. 
Harrison, W. G. and Platt, T.: Photosynthesis-irradiance relationships in polar and temperate phytoplankton populations, Polar. Biol., 5, 153-164, 1986.

Harrison, W. G., Platt, T., and Lewis, M. R.: The utility of lightsaturation models for estimating marine primary productivity in the field: A comparison with conventional "simulated" in situ methods. Can. J. Fish. Aquat. Sci., 42, 864-872, 1985.

Hill, V. J., Matrai, P. A., Olson, E., Suttles, S., Steele, M., Codispoti, A., and Zimmerman, R. C.: Synthesis of integrated primary production in the arctic ocean: II. In situ and remotely sensed estimates, Progr. Oceanogr., 110, 107-125, doi:10.1016/j.pocean.2012.11.00, 2013.

Huot, Y., Babin, M., Bruyant, F., Grob, C., Twardowski, M. S., and Claustre, H.: Relationship between photosynthetic parameters and different proxies of phytoplankton biomass in the subtropical ocean, Biogeosciences, 4, 853-868, doi:10.5194/bg-4853-2007, 2007.

Irwin, B., Hodgson, M., Dickie, P., and Platt, T.: Phytoplankton Productivity Experiments in Baffin Bay and Adjacent Inlets, $22 \mathrm{Au}-$ gust to 18 September 1977, Fisheries and Marine Service, data report 82, 1978a.

Irwin, B., Evans, P., and Platt, T.: Phytoplankton productivity experiments and nutrient measurements in the labrador sea from 15 october to 31 october 1977, Fisheries and Marine Service, data report $83,1978 b$.

Irwin, B., Harrison, W. G., Gallegos, C. L., and Platt, T.: Phytoplankton productivity experiments and nutrient measurements in the Labrador Sea, Davis Strait, Baffin Bay and Lancaster Sound from 26 August to 14 September 1978, Canadian data report Fisheries and Aquatic Sciences No. 213, 1980.

Irwin, B., Dickie, P., Hogson, M., and Platt, T.: Primary production and nutrients on the Labrador Shelf, in Hudson Strait and Hudson Bay in August and Spetember 1982, Canadian data report of fisheries and aquatic sciences No. 692, 1982.

Irwin, B., Harris, L., Hogson, M., Horn, E., and Platt, T.: Primary Productivity and Nutrient Measurements in Northern Foxe Basin, NWT from 27 August to 7 September 1981, Canadian data report of fisheries and aquatic sciences No. 385, 1983a.

Irwin, B., Harris, L., Dickie, P., Lindley, P., and Platt, T.: Phytoplankton productivity in the eastern Canadian Arctic during July and August 1980, Canadian data report of fisheries and aquatic sciences No. 386, 1983 b.

Irwin, B., Dickie, P., Lindley, P., and Platt, T.: Phytoplankton productivity in Lancaster Sound and approaches during the summer of 1979, Canadian data report of fisheries and aquatic sciences No. 423, 1984a.

Irwin, B., Horne, E. P. W., Boulding, E., and Platt, T.: Phytoplankton productivity in Jones Sound during August and September 1984, 1984b.

Irwin, B., Platt, T., and Caverhill, C.: Primary production and other related measurements in the Eastern Canadian Arctic during the summer of 1983, Canadian data report of fisheries and aquatic sciences No. 510, 1985.

Jassby, A. D. and Platt, T.: Mathematical formulation of the relationship between photosynthesis and light for phytoplankton, Limnol. Oceanogr., 21, 540-547, 1976.

Lavoie, D., Denman, K. L., and Macdonald, R. W.: Effects of future climate change on primary productivity and export fluxes in the Beaufort Sea, J. Geophys. Res.-Oceans., 115, C04018,
doi:10.1029/2009JC005493, 2010.

Legendre, L., Gosselin, M., Hirche, H. -J., Kattner, G., and Rosenberg, G.: Environmental control and potential fate of sizefractionated phytoplankton production in the Greenland Sea (75 N), Mar. Ecol.-Prog. Ser., 98, 297-313, 1993.

Li, W. K., McLaughlin, F. A., Lovejoy, C., and Carmack, E. C.: Smallest algae thrive as the Arctic Ocean freshens, Science, 326, 539, doi:10.1126/science.1179798, 2009.

Longhurst, A., Sathyendranath, S., Platt, T., and Caverhill, C.: An estimate of global primary production in the ocean from satellite radiometer data, J. Plankton. Res., 17, 1245-1271, 1995.

Lovejoy, C., Vincent, W. F., Bonilla, S., Roy, S., Martineau, M. -J., Terrado, R., Potvin, M., Massana, R., and Pedrós-Alió, C.: Distribution, phylogeny, and growth of cold-adapted picoprasinophytes in arctic seas, J. Phycol., 43, 78-89, doi:10.1111/j.15298817.2006.00310.x, 2007.

Maccracken, J. G.: Pacific Walrus and climate change: observations and predictions, Ecol. Evol., 2, 2072-2090, doi:10.1002/ece3.317, 2012.

MacIntyre, H. L., Kana, T. M., Anning, T., and Geider, R. J.: Photoacclimation of photosynthesis irradiance response curves and photosynthetic pigments in microalgae and cyanobacteria, J. Phycol., 38, 17-38, 2002.

Marra, J.: Approaches to the measurement of plankton production, in: Phytoplankton productivity: Carbon assimilation in marine and freswater ecology, edited by: Williams, P. J. Le B., Thomas, D. N., and Reynolds, C. S., 78-108, Wiley-Blackwell, 2002.

Morel, A.: Available, usable, and stored radiant energy in relation to marine photosynthesis, Deep-Sea. Res., 25, 673-687, 1978.

Morel, A.: Light and marine photosynthesis: a spectral model with geochemical and climatological implications, Prog. Oceanogr., 26, 263-306, 1991.

Pabi, S., van Dijken, G. L., and Arrigo, K. R.: Primary production in the Arctic Ocean, 1998-2006, J. Geophys. Res-Oceans., 113, C09003, doi:10.1029/2007JC004578, 2008.

Palmer, M. A., Arrigo, K. R., Mundy, . J., Ehn, J. K., Gosselin, M., Barber, D. G., Martin, J., Alou, E., Roy, S., and Tremblay, J. -É.: Spatial and temporal variation of photosynthetic parameters in natural phytoplankton assemblages in the Beaufort Sea, Canadian Arctic, Polar. Biol., 34, 1915-1928, doi:10.1007/s00300011-1050-x, 2011.

Pesant, S., Legendre, L., Gosselin, M., Smith, R. E. H., Kattner, G., and Ramseier, R. O.: Size-differential regimes of phytoplankton production in the Northeast Water Polynya (77-81 N), Mar. Ecol.-Prog. Ser., 142, 75-86, 1996.

Platt, T., Gallegos, C. L., and Harrison, W. G.: Photoinhibition of photosynthesis in natural assemblages of marine phytoplankton, J. Mar. Res., 38, 687-701, 1980.

Platt, T., Sathyendranath, S., Forget, M. H., White, G. N., Caverhill, C., Bouman, H., Devred, E., and Son, S. H.: Operational estimation of primary production at large geographical scales, Remote Sens. Environ., 112, 3437-3448, doi:10.1016/j.rse.2007.11.018, 2008.

Ras, J., Claustre, H., and Uitz, J.: Spatial variability of phytoplankton pigment distributions in the Subtropical South Pacific Ocean: comparison between in situ and predicted data, Biogeosciences, 5, 353-369, doi:10.5194/bg-5-353-2008, 2008.

Rey, F.: Photosynthesis-irradiance relationships in natural phytoplankton populations of the Barents Sea, Polar. Res., 10, 105- 
116, 1991.

Sakshaug, E. and Slagstad, D.: Light and productivity of phytoplankton in polar marine ecosystems: a physiological view, Polar. Res., 10, 69-86, 1991.

Sallon, A., Michel, C., and Gosselin, M.: Summertime primary production and carbon export in the southeastern Beaufort Sea during the low ice year of 2008, Polar. Biol., 34, 1989-2005, doi:10.1007/s00300-011-1055-5, 2011.

Stirling, I. and Derocher, A. E.: Effects of climate warming on polar bears: a review of the evidence, Glob. Change. Biol., 18, 26942706, doi:10.1111/j.1365-2486.2012.02753.x, 2012.

Stroeve, J. C., Kattsov, V., Barrett, A., Serreze, M., Pavlova, T., Holland, M., and Meier, W. N.: Trends in Arctic sea ice extent from CMIP5, CMIP3 and observations, Geophys. Res. Lett., 39, L16502, doi:10.1029/2012GL052676, 2012.

Subba Rao, D. V. and Platt, T.: Primary production of Arctic waters, Polar. Biol., 3, 191-201, 1984.
Uitz, J., Claustre, H., Morel, A., and Hooker, S. B.: Vertical distribution of phytoplankton communities in open ocean: An assessment based on surface chlorophyll, J. Geophys. Res.-Oceans., 111, C08005, doi:10.1029/2000JC000597, 2006.

Uitz, J., Huot, Y., Bruyant, F., Babin, M., and Claustre, H.: Relating phytoplankton photophysiological properties to community structure on large scales, Limnol. Oceanogr., 53, 614-630, 2008.

Wang, M. and Overland, J. E.: A sea ice free summer Arctic within 30 years: An update from CMIP5 models, Geophys. Res. Lett., 39, L18501, doi:10.1029/2012GL052868, 2012.

Walsh, J. E., Anisimov, O., Hagen, J. O. M., Jakobsson, T., Oerlemans, J., Prowse, T. D., and Shiklomanov, I.: Cryosphere and hydrology, in: Arctic climate impact assessment, 183-242, Cambridge, Cambridge University Press, 2005.

Yamamoto, A., Kawamiya, M., Ishida, A., Yamanaka, Y., and Watanabe, S.: Impact of rapid sea-ice reduction in the Arctic Ocean on the rate of ocean acidification, Biogeosciences, 9, 2365-2375, doi:10.5194/bg-9-2365-2012, 2012. 